\title{
Log Sawing Position Optimization using Computed Tomography Scanning
}

This is an Accepted Manuscript of an article published by Taylor \& Francis in Wood Material Science and Engineering on 08/04/2014, available online:

http://www.tandfonline.com/doi/abs/10.1080/17480272.2014.904430 


\title{
Log Sawing Position Optimization using Computed Tomography Scanning
}

\author{
Magnus Fredriksson ${ }^{1}$ \\ ${ }^{1}$ Luleå University of Technology, Skellefteå Campus, SE-931 87 Skellefteå, Sweden. \\ Telephone: +46(0)910-585708, Fax: +46(0)910-585399, E-mail: magnus.1.fredriksson@1tu.se
}

\begin{abstract}
When disjoining a log, several factors affect the value of the sawn timber. There are log features, such as outer shape, knots, rot and so on. There are also sawing parameters, such as sawing pattern, log position etc. If full information about log features is available, sawing parameters can be adapted in order to maximize product value in sawmills. This is soon possible, since computed tomography (CT) scanners for the sawmill industry are being realized.
\end{abstract}

This study aimed at investigating how CT data can be used to choose rotational position, parallel displacement and skew of sawlogs, to maximize the value of the sawn products. The study was made by sawing simulation of 269 CT scanned logs of Scots pine (Pinus sylvestris L.) and Norway spruce (Picea abies (L.) H.Karst.).

The results showed that value recovery could be improved by $13 \%$ in average, compared to a sawing position based on log outer shape, and $21 \%$ compared to sawing logs centered and horns down.

It can be concluded that a CT scanner, used in a sawline to optimize sawing parameters, has a large potential for increasing value recovery and thus profit.

Keywords: CT scanning, Log positioning, Sawing simulation, Value recovery, Wood processing 


\section{Introduction}

In the sawmill industry, one long-withstanding dream is to be able to see inside logs, and to choose how to break them down individually, based on the internal wood structure. This has to some extent been realized by X-ray scanning technology developed for, and used in, sawmills (Pietikäinen 1996, Oja et al. 1998, Grundberg 1999). However, the discrete $\mathrm{X}$-ray technology employed today is based on a small number of scan directions, which means that the available information of internal wood features is restricted, Figure 1. The commercial X-ray solutions available today are mainly based on discrete X-ray scanning, such as those supplied by RemaControl (two scanning directions), Bintec (one to six directions) and Microtec (two or four directions). A small amount of scan directions means that the information available is a few two-dimensional images of the log, as opposed to three-dimensional information of the wood structure. Little can be said about for instance the position of knots in a cross-section of a log. Discrete X-ray scanners are used for making general judgments of log quality, mainly for log sorting purposes.

\section{CT scanning and possibilities for log positioning optimization}

Other possibilities to scan sawlogs in real time using X-ray are being realized, and a high speed computed tomography (CT) scanner is being developed and used in sawmills (Giudiceandrea et al. 2011). Figure 2 shows a stack of CT images of a Norway spruce (Picea abies (L.) Karst.) log. CT scanning of wood has been used extensively in research (Bhandarkar et al. 1999, Grundberg 1999, Moberg 2000, Alkan et al. 2007, Brüchert et al. 2008, Hou et al. 2009, Longuetaud et al. 2012), rather than sawmill applications so far, even if some proposals for a technical solution have been presented (Magnusson Seger and Danielsson 2003, An and Schajer 2014). Wei et al. (2011) has published a review covering most of the research done on CT scanning of wood up until the year 2010.

A CT scanner enables detection of for instance knots and their position in logs, and also the outer shape. With this information available it is possible to optimize the position of a log when sawing, to improve the value of the sawn timber.

A log positioning optimization will in many cases change the industrial praxis of today, which is to saw logs centered and in the horns down position, or to use an optical 3D scanner to optimize log positioning based on outer shape. These positioning strategies result in a high volume recovery when only outer shape data is available (Maness and Donald 1994, Lundahl and Grönlund 2010). However, this might not necessarily be the optimal strategy for each individual log when value recovery is considered. Value recovery is to a large extent based on quality grading of visual board features, which means that an optimal strategy for value recovery might differ from an optimal strategy for volume recovery. 

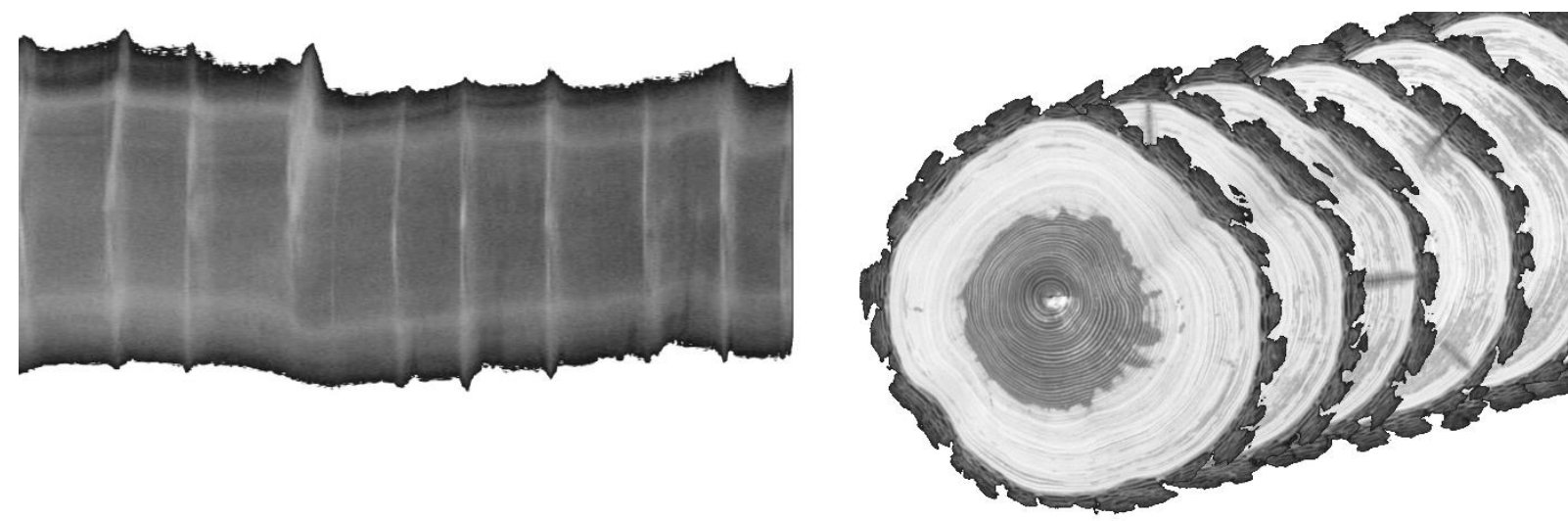

Figure 1. Two dimensional image produced by a discrete X-ray scanner.

Figure 2. Stack of cross section images produced by a CT scanner which forms a three dimensional description of a log when added together.

\section{Previous work}

It has been shown in earlier research (Lundahl and Grönlund, 2010) that it is possible to increase volume recovery in the breakdown of logs by several percent, by choosing an optimal rotational position based on CT data. For individual logs, this number is even higher. This study was made on Scots pine (Pinus sylvestris L.), and for Swedish sawmills and quality rules. A study on a similar material made by Berglund et al. (2013), indicates a potential value recovery increase of about $13 \%$, when optimizing rotational position and comparing to horns down, using internal log features as well as external. Another study, by Todoroki and Rönnqvist (1999), shows a potential value recovery increase of $16 \%$ when practicing live sawing and optimizing sawing parameters based on CT data. Their study was made on Radiata pine (Pinus radiata D. Don). Finally, Rinnhofer et al. (2003) shows that it is possible to gain value for lamella production by up to $23 \%$, by CT scanning logs and letting a sawyer decide the breakdown according to the CT images. None of these studies has tried to find the possible value gain for optimizing the combination of log rotation, parallel displacement and skew based on CT data, which would be an important factor in assessing the economic implications of investing in a CT scanner for a sawmill.

\section{Problem statement and limitations}

In order to find out whether or not a CT scanner has the potential of being a profitable investment, it is necessary to quantify the increase in value recovery that is possible to achieve with such a scanner by improved log positioning. Furthermore, an analysis of how often the centered, horns down position is the optimal solution for sawing a log is needed, for a better understanding of the mechanisms that affect sawing value recovery. To investigate this, computer simulation is a suitable method since it allows testing the same material several 
times, and makes it possible to study the problem in a smaller time frame than in a real system (Law 2007).

The objectives of this study were to:

- Quantify the value recovery increase that is possible to achieve by choosing rotational position, parallel displacement, and skew of logs being sawn in a Scandinavian sawmill, based on CT data rather than just the outer shape of logs.

- Analyze to what extent the optimal position of a sawlog is at the centered, horns down position or a displaced, skewed position with a different rotational position.

It was assumed that the production setup when a CT scanner is introduced, is rather unchanged compared to a traditional sawmill, but that it is possible to control rotational position, parallel displacement and skew of each individual log when sawing, based on CT information. No sensitivity analysis of errors in measurements and/or log positioning was made.

\section{Materials and methods}

The stem bank

The study was based on the 712 Scots pine (Pinus sylvestris L.) and 750 Norway spruce (Picea abies (L.) Karst.) logs in the Swedish Pine Stem Bank (Grönlund et al. 1995) and the European Spruce Stem Bank (Berggren et al. 2000). The stem bank trees, from well-documented sites at different locations in Europe, have been documented thoroughly regarding both tree properties and silvicultural treatments. They have been scanned with a medical CT scanner (Siemens SOMATOM AR.T) to record internal properties such as knots, and also the outer shape of the log (Grönlund et al. 1995). Knots are described by a parameterized model, which takes into account curvature of the knot and diameter in two log directions, tangential and longitudinal. Each knot is divided into a living part and a dead part. Details on the log model are given by Grönlund et al. (1995) and Nordmark (2005).

In the main trial of this study, a sample of logs were used to reduce the time needed for simulations. The sample was chosen to be as representative as possible for the rest of the stem bank with regard to log and growth site properties. The sampling was made by using every fourth stand of trees in the stem bank, until more than $250 \operatorname{logs}$ was used, as a compromise between maximizing the size of the material and at the same time finalizing the study within a reasonable timeframe. This resulted in a non-biased selection with a wide range of logs, Table 1. 123 Scots pine logs and 146 Norway spruce logs were used, in total $269 \operatorname{logs}$. Both butt logs, middle logs and top logs were included.

Table 1. Data for the logs used in this study. Taper was calculated as the diameter at the middle 
of the log minus the top diameter, divided by length. Ovality was calculated using the cross section $10 \mathrm{~cm}$ from the top end of each $\mathrm{log}$, as maximum diameter minus minimum diameter divided by minimum diameter.

\begin{tabular}{llllll}
\hline Feature & Min & Max & Mean & Standard deviation & Unit \\
\hline Top diameter & 117 & 379 & 202 & 58.9 & $\mathrm{~mm}$ \\
Site index & 16 & 33 & 26 & 5 & $\mathrm{~m}$ \\
Length & 346 & 549 & 440 & 42 & $\mathrm{~cm}$ \\
Taper & 0.10 & 12 & 3.8 & 2.0 & $\mathrm{~mm} / \mathrm{m}$ \\
Ovality & 1.3 & 35 & 6.4 & 3.5 & $\%$
\end{tabular}

\section{Sawing simulation software description}

The stem bank can be used for sawing simulation through the simulation software Saw2003, developed by Nordmark (2005). The input is log models, based on the CT scanned logs of the stem bank. Saw2003 models a sawmill that employs cant sawing with two sawing machines, with curve sawing in the second saw, edging and trimming. The latter two are value-optimized according to timber prices and grading criteria. It is also possible to control positioning of the logs during sawing.

Grading of the sawn boards in Saw2003 is done according to the Nordic Timber Grading Rules (Anonymous 1997). Boards are graded into three quality classes, A, B or C, where $\mathrm{A}$ is the class with the strictest requirements. The grading is based on knots and wane only, since other board features, such as pitch pockets or rot, are not represented in the stem bank. An example of a log model used in Saw2003 is shown in Figure 3, with outer shape and knots.

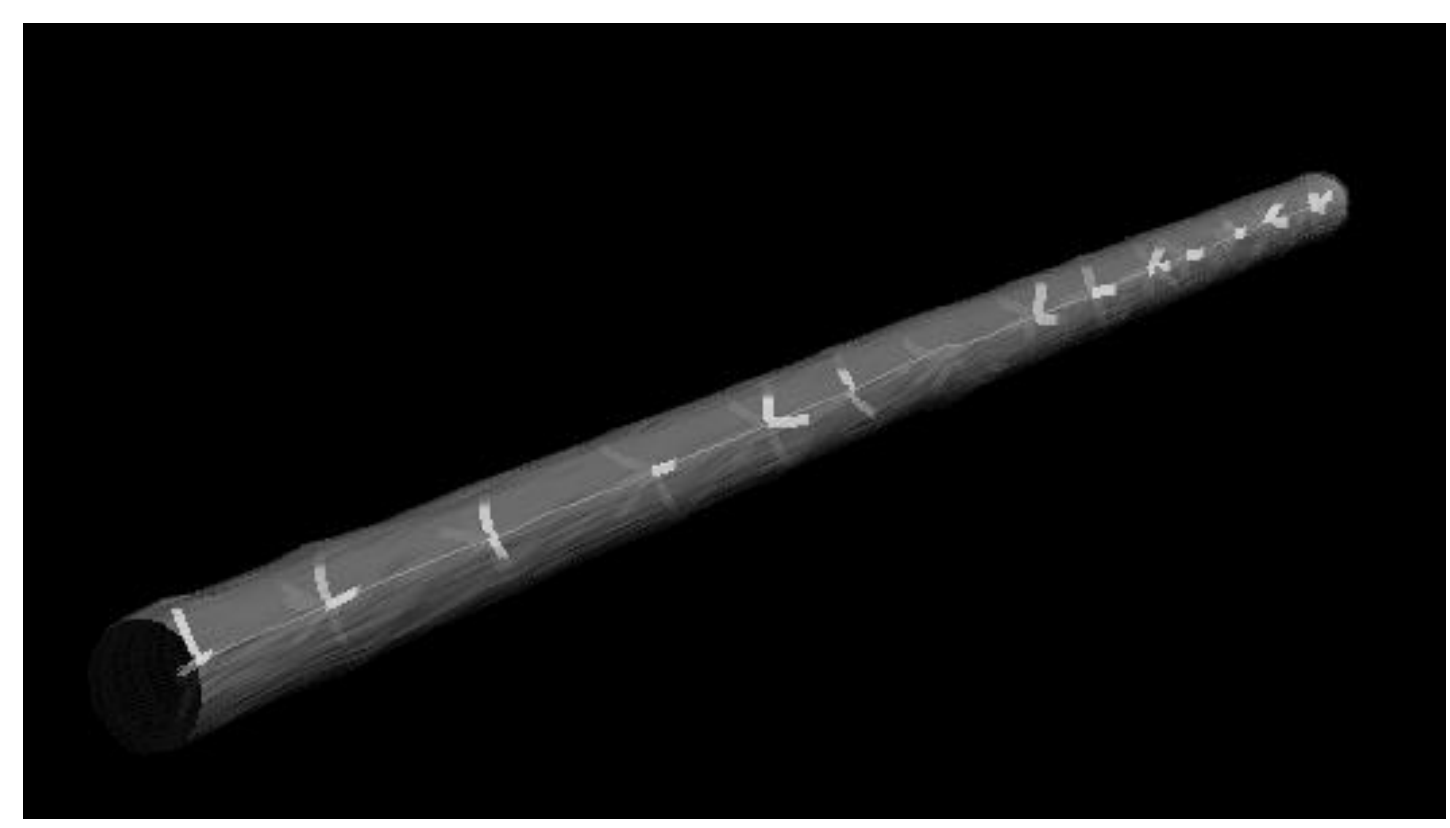

Figure 3. Example of log model used in this study. 
The sawing simulation results in virtual boards with information about knots, dimensions, value and so forth. Saw2003 has been used extensively in earlier research (Chiorescu and Grönlund 1999, Nordmark 2005, Moberg and Nordmark 2006, Lundahl and Grönlund 2010).

\section{Settings used in the simulator}

The sawing pattern for each log was chosen according to the top diameter, a manner typical of Scandinavian sawmills. The corresponding sawing patterns for different top diameters are presented in Table 2. Since Saw2003 employs value-optimized edging and trimming, the price relation between different board qualities affects the simulation result. This is for instance shown in Berglund et al. (2013). The prices of sawn timber used in this study were 185,160 and $100 € / \mathrm{m}^{3}$, for center boards of A, B and C quality, respectively. For the sideboards, the prices were 300,140 and $110 € / \mathrm{m}^{3}$, also for $\mathrm{A}, \mathrm{B}$ and $\mathrm{C}$ quality. By-products were priced at $20 € / \mathrm{m}^{3}$. Sideboards were edged to widths of $75,100,115,125$, $127,150,175,200$ or $225 \mathrm{~mm}$, with a fixed thickness of 19 or $25 \mathrm{~mm}$ depending on the position in the sawing pattern. All boards were trimmed to module lengths of $1800+\mathrm{n} \times 300$ $\mathrm{mm}$ modules, $\mathrm{n}$ being the number of length modules. The logs were curve sawn, so in the second saw the saw kerf followed the curve of the log.

Table 2. List of sawing patterns used in this study. Lower diameter limit = smallest top diameter allowed for logs within this sawing pattern. Upper diameter limit = largest top diameter allowed for sawing pattern. Width $=$ nominal width of centerboards (main yield). Thickness $=$ nominal thickness of centerboards. Sideboards were edged to various sizes depending on value.

\begin{tabular}{lllll}
\hline Lower diameter limit & Upper diameter limit & No. of centerboards & Width & Thickness \\
\hline 0 & 129 & 2 & 75 & 38 \\
130 & 149 & 2 & 100 & 38 \\
150 & 169 & 2 & 100 & 50 \\
170 & 184 & 2 & 125 & 50 \\
185 & 194 & 2 & 125 & 63 \\
195 & 209 & 2 & 150 & 50 \\
210 & 219 & 2 & 150 & 63 \\
220 & 229 & 2 & 175 & 50 \\
230 & 249 & 2 & 175 & 63 \\
250 & 264 & 2 & 200 & 63 \\
265 & 284 & 2 & 200 & 75 \\
285 & 304 & 2 & 225 & 75
\end{tabular}




\section{Log positioning}

The three types of log positioning investigated in this study are presented in Figure 4. When a $\log$ is rotated, it is turned around its central axis. Parallel displacement of a log means that it is moved in a lateral direction but not turned in any way. When a log is skewed, one end (butt or top) of the log is moved, turning the log around the other end. Rotation can take place in the first saw only, while parallel displacement and skew can be done in both saws. In the second saw, the cant resulting from the first saw is sawn, thus no rotation can be done. Parallel displacement and skew is achieved by moving log positioners, two in the first saw and two in the second, located at the butt end or top end of the log or cant. In total, five different positioning parameters were tested: Parallel displacement and skew in two saws, and rotation in the first saw.
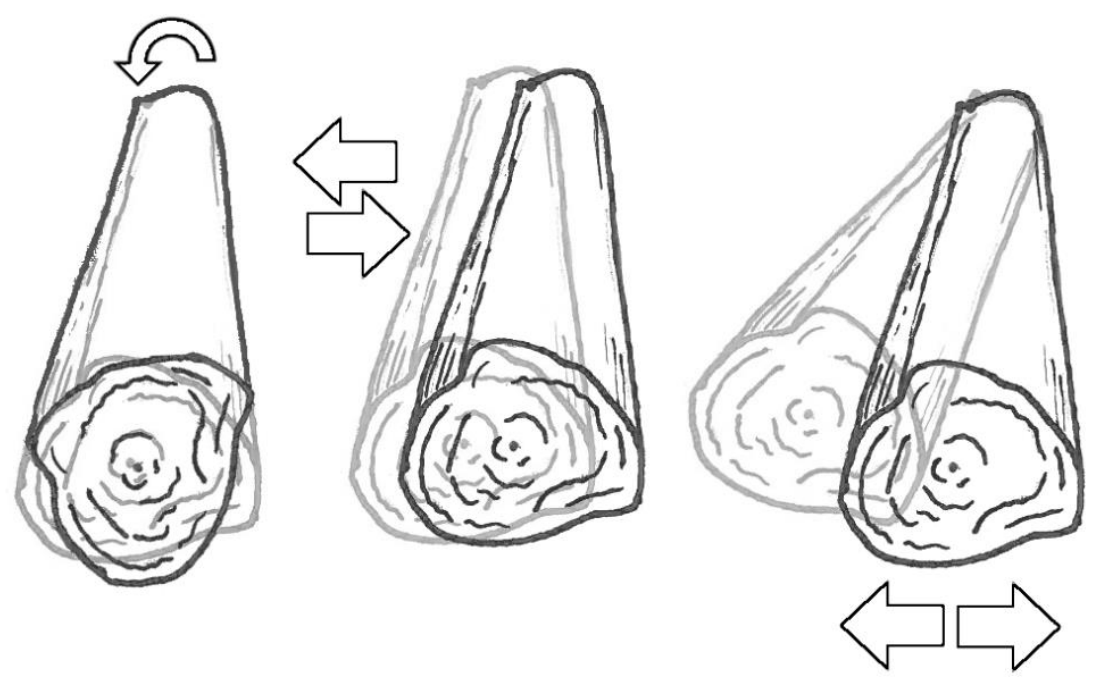

Figure 4. The three types of positioning displacement studied, from left to right: rotation, parallel displacement and skew.

A screening trial was made to investigate in what range of displacement it was meaningful to search for a high value solution. The reason for this was to save computational time in further trials. All logs in the stem bank were sawn 180 times, turning the log one degree each time, to find the rotational position giving the highest value in the centered position. Since the sawing patterns were symmetrical, only a half turn of each log was needed. Then, seven different positions of the positioners, and all combinations of these, were tested in a range of $\pm 21 \mathrm{~mm}$, in $7 \mathrm{~mm}$ steps. This resulted in $180+7^{4}=2581$ simulations per $\log$, and this choice of positions was made as a compromise between available computational time 
and to test as many positions as possible. Since all combinations of positioner positions were tested, both parallel displacement and skew were achieved. The positions giving the highest value were recorded. In this case, only $3 \%$ of the best positions were outside the $\pm 14 \mathrm{~mm}$ positioner range. Thus this was chosen as the range to use in further trials.

\section{The potential of finding the best sawing position}

The sawing simulation of the 269 stem bank logs were done using three different treatments of the logs, meaning three different simulation runs:

a) The first treatment was done using data on both knots and outer shape of the logs. Each degree in a half turn of $180^{\circ}$ of rotation was tested, and five different positions for the four log positioners and all in combination, meaning that each $\log$ was disjoined 112500 times in Saw2003. The range of positions for each positioner was $\pm 14 \mathrm{~mm}$, in steps of $7 \mathrm{~mm}$. The combination of positioning parameters resulting in the highest value of the sawn timber was recorded, together with product value.

b) A similar optimization was done while only using outer shape information. After optimization, each log was sawn again, with knots, and the sawn timber value was recorded. This corresponds to the type of optimization that is possible to achieve using a 3D scanner, and was used as a reference for comparing value recovery.

c) All logs were sawn horns down, centered and without skew to be used as a second reference.

How good is the centered, horns down position?

The results from the positioning parameter optimization using both knots and outer shape were analyzed with regard to how often the best position is at the centered, horns down position, and how often it is in any other position.

\section{Results and discussion}

\section{The potential of finding the best sawing position}

The choice of the best position among those 112500 tested for each CT scanned log, using treatment a), resulted in a value of the sawn goods that was in average 13\% (14\% for pine and $12 \%$ for spruce) higher than for the best position obtained by using outer shape data only, or treatment $b$ ). The change in volume recovery was merely $+0.50 \%$, since the aim was not volume optimization but value optimization. However, this shows that access to knot information can increase volume recovery as well, if the trimming and edging operations are taken into account. These operations cannot be predicted in the same way by only using outer shape data of the log, as when internal log features such as knots are available. The reason for 
this is that trimming and edging are made using grading rules for knots.

When comparing the optimized position in treatment a) to the centered, horns down position, treatment $c)$, the value change was in average $+21 \%(+24 \%$ for pine and $+20 \%$ for spruce). The increase in volume recovery was $8 \%$. This shows that for individual logs, full information about knots and outer shape can increase both value and volume recovery to a large extent, compared to when practically nothing is known about the knots. The value change compared to a centered horns down position, for each of the 123 pine logs, is presented in Figure 5. The same value change for the 146 spruce logs is shown in Figure 6. The reason for the different levels of value potential between spruce and pine is probably that the pine logs had a smaller average top diameter than the spruce logs in this study, with an average top diameter of $178 \mathrm{~mm}$ compared to $222 \mathrm{~mm}$ for the spruce logs. This affects the relative value change for individual logs.

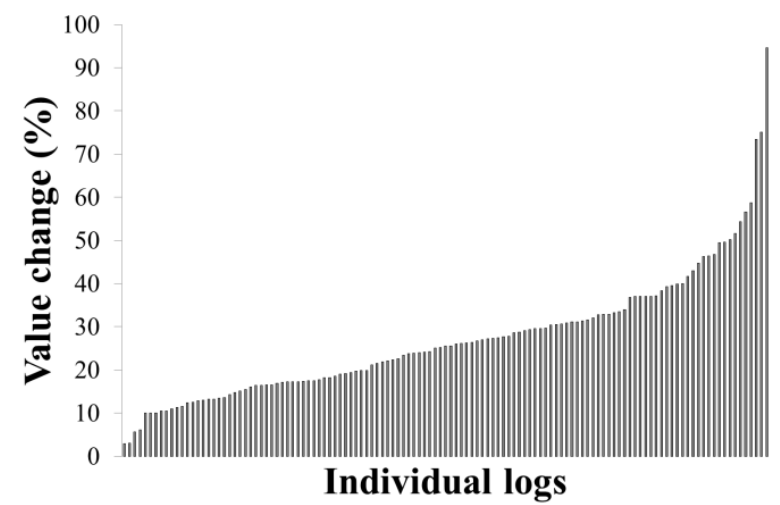

Figure 5. Value change between optimized sawing position (treatment a) and centered, horns down position (treatment c) for the 123 pine logs studied. The data is sorted by magnitude of the value change. The percentage is calculated as the absolute value change divided by the value for the centered, horns down position.

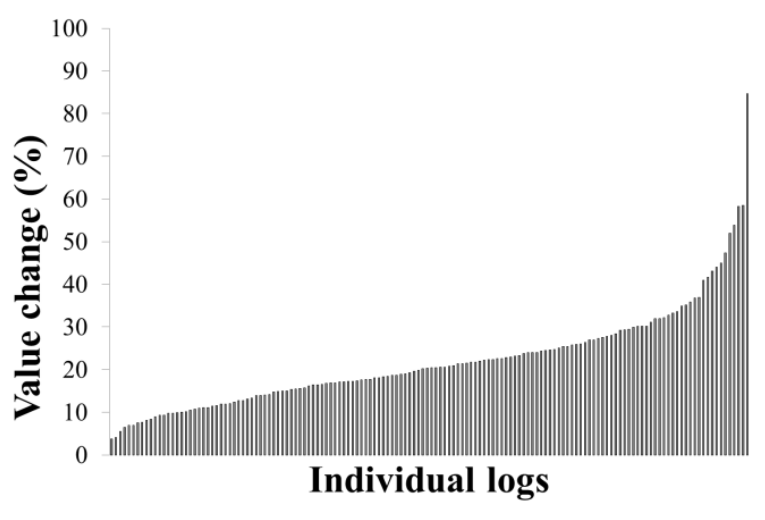

Figure 6. Value change between optimized sawing position (treatment a) and centered, horns down position (treatment c) for the 146 pine logs studied. The data is sorted by magnitude of the value change. The percentage is calculated as the absolute value change divided by the value for the centered, horns down position.

It should be noted that not all possible positions and combinations of positioning parameters were tested, since that would require a large number of simulations and therefore time. There could be positions outside the $\pm 14 \mathrm{~mm}$ range, or between the chosen steps, that are more favorable. This means that the result obtained here was not a full optimization, but a large test of positioning parameter combinations. The first screening trial reduces this risk, since $\pm 14 \mathrm{~mm}$ was a range were $97 \%$ of the optimal positions were located in that case. 
When optimizing the sawing position in treatment a), none of the logs had its best position in the centered, horns down position. The distributions of the best choice of the five positioning parameters are presented in Figure 7 and Figure 8. Figure 8 shows the rotational angle as angular distance to the horns down position. The smallest absolute angular distance between the optimal angle and the horns down angle was considered as the angular distance, also considering the opposite of each angle since the sawing pattern was symmetrical. Thus the range of possible angular distances was between 0 and $90^{\circ}$. As can be seen in Figure 6 , the centered position is in general a rather good choice for a large number of logs, when little is known about for instance knots within the individual logs. Furthermore, a centered position is more often favorable in the first saw than in the second saw. This can be explained by the fact that a displaced log in the first saw often produces wane on both center boards, while a displaced cant in the second saw is less sensitive to wane.

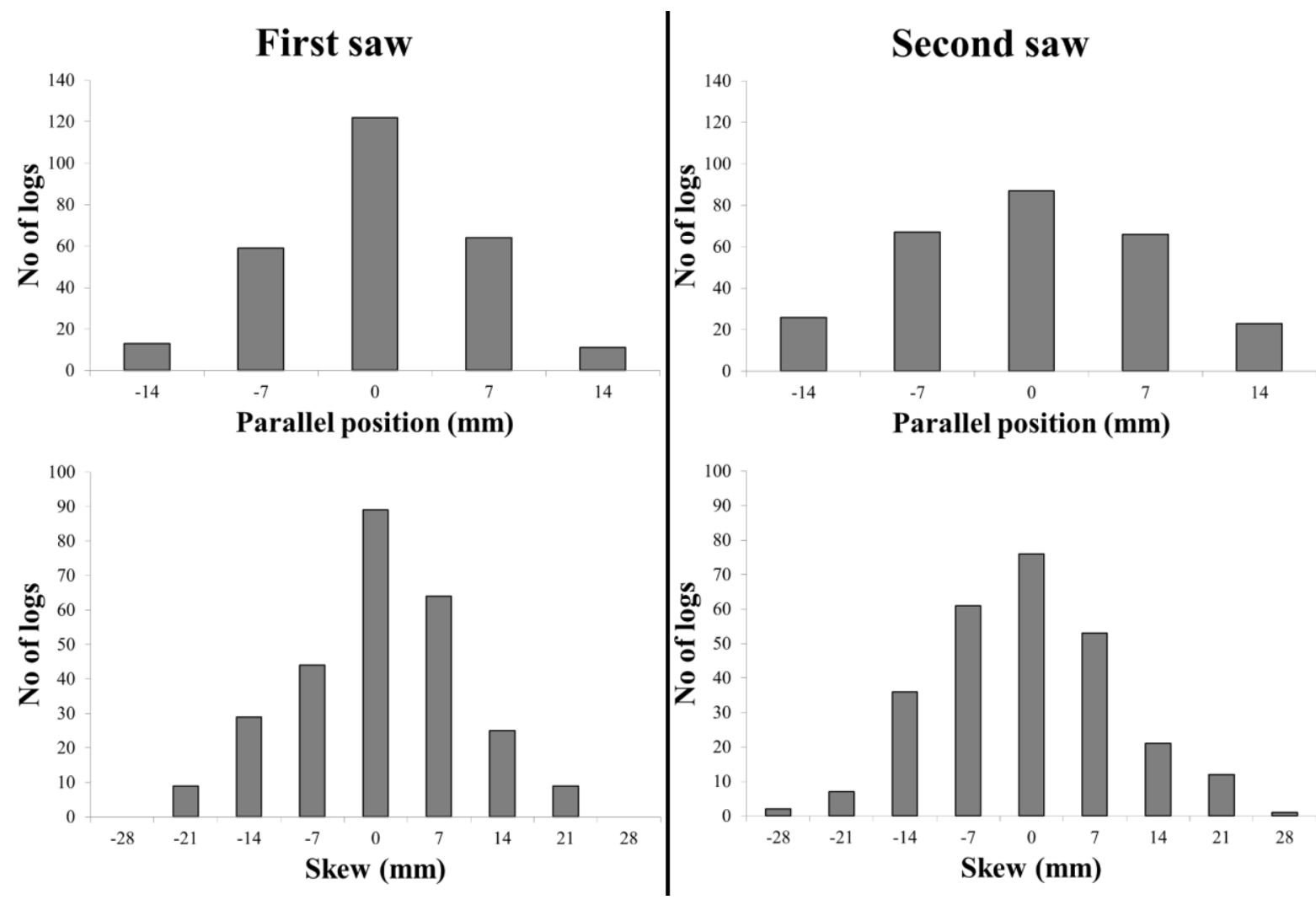

Figure 7. Distribution of optimal positioning parameters in treatment a), when having access to CT data. From top left to bottom right: distribution of best parallel displacement in the first saw, best parallel displacement in the second saw, best skew in the first saw and best skew in the second saw. The zero value on the $\mathrm{x}$-axis corresponds to a centered log or cant in the parallel displacement case, and to zero skew in the skew case. The bars show the amount of logs that have their best position at the corresponding value. Note that the positioner range of $\pm 14 \mathrm{~mm}$ results in a skew range of $\pm 28 \mathrm{~mm}$, since skew is the difference between back and front positioner. 


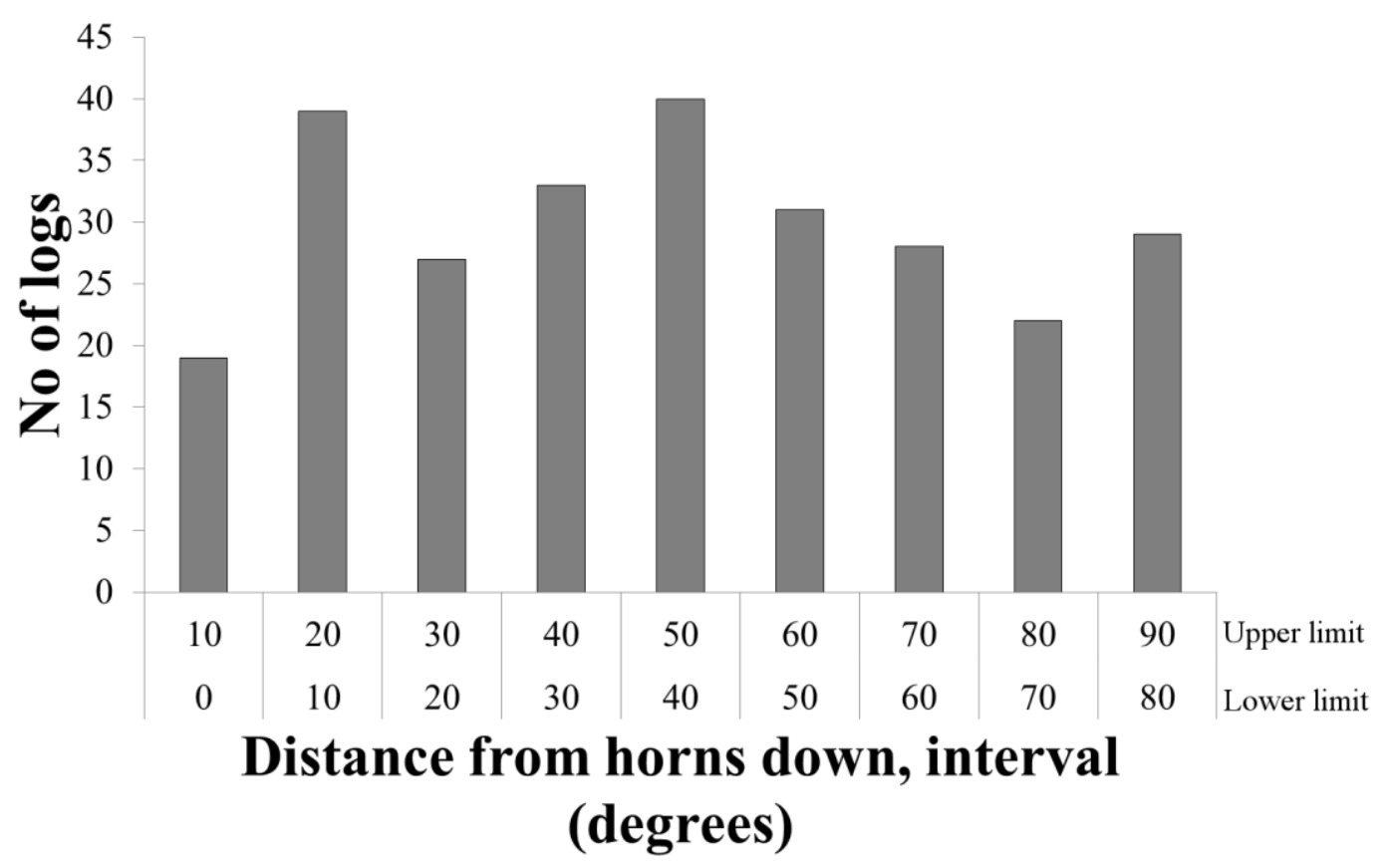

Figure 8. The best rotational position for all logs. The bars show the amount of logs that have their best rotational position at the corresponding angle interval. The zero value on the $\mathrm{x}$-axis corresponds to horns down. Note that this is the best rotational position in combination with the other types of displacement: parallel displacement and skew.

Perhaps a bit surprisingly, the optimal rotational position is quite evenly distributed in Figure 8, and the positions closest to horns down are not significantly more common than the other positions, when all five positioning parameters can be controlled at the same time. Would the logs be centered in both saws though, it is more probable that the best rotational position would be horns down, especially when curve sawing. For volume recovery, rather than value recovery, the horns down position is still a good option when little is known about individual logs and their external and internal features. This is the reason why a centered, horns down position has been used as an industrial praxis, when no CT scanners have been available. Today however, this information is emerging through new technology, which means that for the many logs that do not have their best position in the centered, horns down position, a large value gain is possible.

The reasons why the centered, horns down position is not always best for an individual log could be several. The position and size of knots on the boards have a large impact on value recovery, and this is not always optimal in the normal sawing position. This has been shown for rotational positioning by Berglund et al. (2013). Furthermore, the surface of a log is not smooth, and bumps, taper, ovality and log curve will affect the recovery in a way that is difficult to predict without sawing simulation.

It should be noted that the simulations made when testing all combinations of positioning parameters were made on a sample of the stem bank. However, since the logs 
were selected in a non-biased way, and the range of log and stand properties is relatively large, the material is fairly representative of the entire stem bank.

One of the limitations of this study is that it is based on Scandinavian industrial praxis, in terms of sorting logs, of sawing and of grading the sawn timber. In this study, the logs were not graded, only sorted according to top diameter and sawn in different ways according to the sorting. Sawmills using a different log sorting practice might experience other optimization results. One possible future study might be how the value potential is affected by log quality. Low quality logs could hypothetically have a larger relative value potential for instance. Also other log features and their impact of the value potential could be studied, like curviness, size, ovality and so on.

An industrial application of the simulation results would be having a CT scanner in the saw line, and scan logs prior to sawing, and performing the optimization during transport. Another possibility is to have the CT scanner at the log sorting station, and tracing each individual log from sorting station to saw line. In that way, logs can be sorted for different purposes and the sawing can be optimized at the same time. This would require some sort of traceability method however, which could be a subject of future studies.

One aspect that was not taken into account here, but will affect the results of log positioning in an industrial application, is positioning errors (Vuorilehto and Tulokas 2007). These errors will be present both in the rotational and translational direction, and will reduce the possible value gain. Also, when positioning errors are present, the best position for sawing a log will not be the same as in the ideal case without positioning errors. Therefore, a strategy for choosing sawing position based on simulation need to be as robust as possible towards positioning errors, by using high value positions with other relatively high value positions nearby in the positioning parameter space, or at least a lack of low value neighbors. If the size of the positioning error is known and is normally distributed, this can be achieved by Gaussian filtering of the obtained data. This was outside the scope of this study, in which no sensitivity analysis was made. It could however be a subject for future work.

Another aspect of a practical application is what happens to the sawn timber after drying, if sawn in a rotational position different from horns down. Fredriksson et al. (2014) showed that for Norway spruce logs with a bow height of more than $15 \mathrm{~mm}$, a rotational position $90^{\circ}$ from horns down results in severe warping of the boards. These curved logs should therefore be sawn in a rotational position closer to horns down, something which has not been taken into account in this study.

The presented results can be seen as a target value for the development of computationally faster value optimization algorithms. If a faster optimization strategy manages to come near this value, it probably works quite well.

\section{Conclusions}


Rotational position, parallel displacement and skew was optimized using sawing simulation, among 112500 different combinations per log, with the aim of maximizing value of the sawn timber. This was done for 269 Scots pine and Norway spruce logs of the Swedish Pine Stem Bank and the European Spruce Stem Bank, and resulted in

- an increased value of $13 \%$ compared to sawing logs based on outer shape 3D data.

- a value change compared to a centered, horns down position of $21 \%$.

The centered, horns down position is favorable for a large batch of logs sawn without knowledge about log features and geometry; with this information available however, a large value can be gained by optimizing sawing position. 


\section{References}

Alkan, S., Zhang, Y., \& Lam, F. (2007). Moisture distribution changes and wetwood behavior in subalpine fir wood during drying using high X-ray energy industrial CT scanner. Drying technology, 25(3), 483-488.

An, Y. \& Schajer, G. (2014). Feature-Specific CT Measurements for Log Scanning: Theory and Application. Experimental Mechanics, 1-10.

Anonymous. (1997). Nordic Timber: Grading rules for pine (Pinus sylvestris) and spruce (Picea abies) sawn timber: Commercial grading based on evaluation of the four sides of sawn timber. Föreningen svenska sågverksmän (FSS), Sweden.

Berggren, G., Grundberg, S., Grönlund, A. \& Oja, J. (2000). Improved spruce timber utilization (STUD). European shared cost research project within FAIR (DGXII/E2), contract no. FAIR-CT96-1915. Final report sub-task A 1.2, database and non-destructive "glass-log" measurements. Technical Report. AB Trätek and Luleå University of Technology.

Berglund, A., Broman, O., Grönlund, A. \& Fredriksson, M. (2013). Improved log rotation using information from a computed tomography scanner. Computers and Electronics in Agriculture, 90, 152-158.

Bhandarkar, S. M., Faust, T.D. \& Tang, M. (1999). Catalog: a system for detection and rendering of internal $\log$ defects using computer tomography. Machine Vision and Applications, 11(4), 171-190.

Brüchert, F., Baumgartner, F. \& Sauter, U. (2008). Ring width detection for industrial purposes-use of ct and discrete scanning technology on fresh roundwood, in: Proceedings of the COST E53 conference, Delft, Netherlands.

Chiorescu, S. \& Grönlund, A. (1999). Validation of a CT-based simulator against a sawmill yield. Forest Product Journal, 50, 69-76.

Fredriksson, M., Broman, O., Persson, F., Axelsson, A. \& Ah Shenga, P. (2014). Rotational position of curved saw logs and warp of the sawn timber. Wood Material Science and Engineering, 9(1), 31-39.

Giudiceandrea, F., Ursella, E. \& Vicario, E. (2011). A high speed CT scanner for the sawmill industry. In: Proceedings of the 17th International Non Destructive Testing and Evaluation of Wood Symposium, 14-16 September 2011, University of West Hungary, Sopron, Hungary. 
Grönlund, A., Björklund, L., Grundberg, S. \& Berggren, G. (1995). Manual för furustambank. (Manual for pine stem bank) Technical Report 1995:19 Luleå University of Technology. Luleå, Sweden. In swedish.

Grundberg, S. (1999). An X-ray LogScanner: a tool for control of the sawmill process. PhD Thesis. Luleå University of Technology, Luleå, Sweden.

Hou, Z. Q., Wei, Q., \& Zhang, S.Y. (2009). Predicting density of green logs using the computed tomography technique. Forest Products Journal, 59(5), 53-57.

Law, A.M. (2007) Simulation modeling and analysis (New York: McGraw-Hill).

Longuetaud, F., Mothe, F., Kerautret, B., Krähenbühl, A., Hory, L., Leban, J. M., \& Debled-Rennesson, I. (2012). Automatic knot detection and measurements from X-ray CT images of wood: A review and validation of an improved algorithm on softwood samples. Computers and Electronics in Agriculture, 85, 77-89.

Lundahl, C.G. \& Grönlund, A. (2010). Increased yield in sawmills by applying alternate rotation and lateral positioning. Forest Product Journal, 60, 331-338.

Magnusson Seger, M., \& Danielsson, P. E. (2003). Scanning of logs with linear cone-beam tomography. Computers and Electronics in Agriculture, 41(1), 45-62.

Maness, T.C. \& Donald, W.S. (1994). The effect of log rotation on value recovery in chip and saw sawmills. Wood and Fiber Science, 26, 546-555.

Moberg, L. (2000). Models of internal knot diameter for Pinus sylvestris. Scandinavian Journal of Forest Research, 15(2), 177-187.

Moberg, L. \& Nordmark, U. (2006). Predicting lumber volume and grade recovery for Scots pine stems using tree models and sawmill conversion simulation. Forest Product Journal, 56, 68-74.

Nordmark, U. (2005). Value recovery and production control in the forestry wood chain using simulation technique. PhD Thesis. Luleå University of Technology, Luleå, Sweden.

Oja, J., Grundberg, S. \& Grönlund, A. (1998). Measuring the outer shape of Pinus sylvestris 
saw logs with an X-ray LogScanner. Scandinavian Journal of Forest Research, 13, 340-347.

Pietikäinen, M. (1996). Detection of knots in logs using x-ray imaging. Ph.D. thesis. VTT Technical Research Centre of Finland. Espoo, Finland.

Rinnhofer, A., Petutschnigg, A. \& Andreu, J.P. (2003). Internal log scanning for optimizing breakdown. Computers and Electronics in Agriculture, 41, 7-21.

Todoroki, C.L. \& Rönnqvist, E. (1999). Combined primary and secondary log breakdown optimisation. The Journal of the Operational Research Society, 50, 219-229.

Vuorilehto, J. \& Tulokas, T. (2007). On log rotation precision. Forest Products Journal, 57, 91-96.

Wei, Q., Leblon, B. \& La Rocque, A. (2011). On the use of x-ray computed tomography for determining wood properties: a review. Canadian Journal of Forest Research, 41, 2120-2140. 